\title{
Social and behavioural HIV/AIDS research in Jordan: a systematic review
}

\author{
E. Alkhasawneh, ${ }^{1}$ L. Ismayilova, ${ }^{2}$ H. Olimat ${ }^{3}$ and N. El-Bassel ${ }^{2}$
}

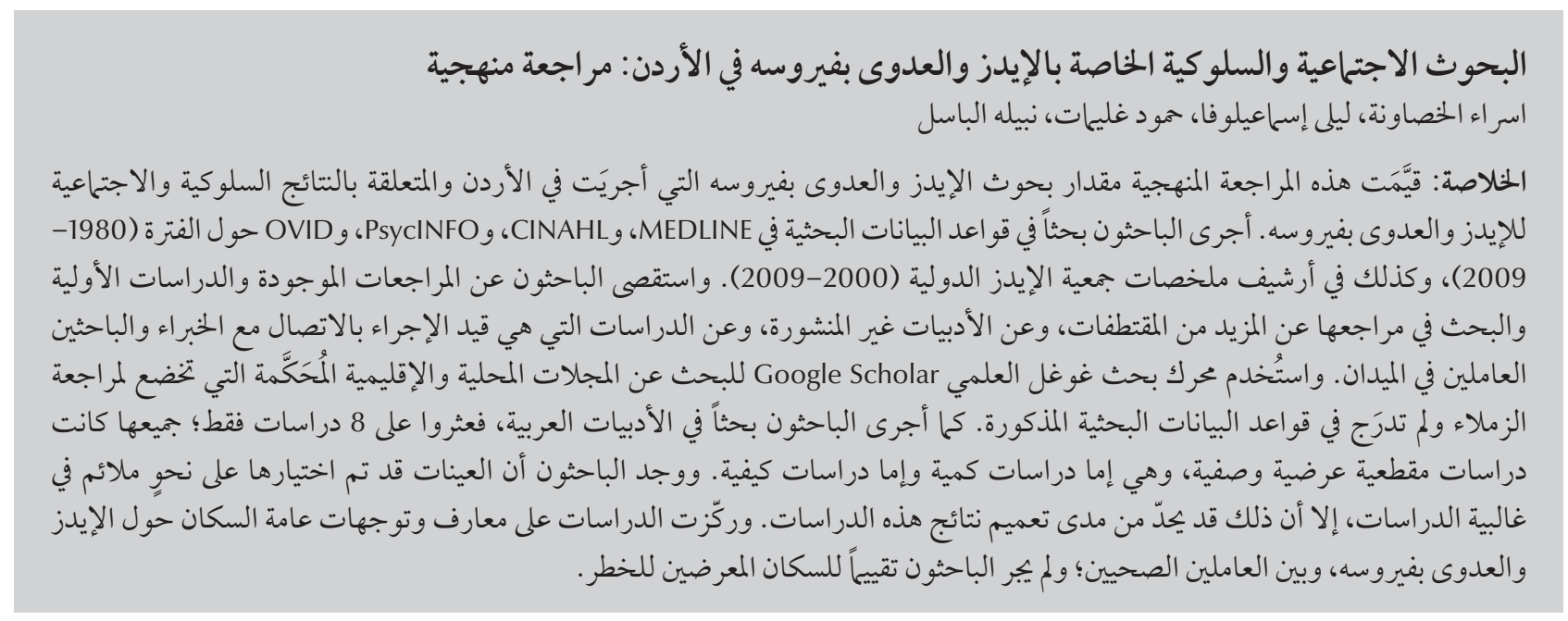

ABSTRACT This systematic review evaluated the extent of HIV/AIDS research conducted in Jordan related to behavioural and/or social outcomes. MEDLINE, CINAHL, PsycINFO and OVID (1980-2009) were searched as well as the International AIDS Society abstract archives (2000-2009). Existing reviews and primary studies were cross-referenced for further citations, and unpublished literature and ongoing trials were searched by contacting experts and active researchers in the field. Google Scholar was used to search in peer-reviewed local or regional journals not included in the above-mentioned databases. Searches were also conducted of Arabic literature. Only 8 relevant studies were identified; all were descriptive cross-sectional studies, either quantitative or qualitative. Convenience samples were used in the majority of the studies, severely limiting the generalizability of the findings. The studies focused on HIV/AIDs knowledge and attitudes in the general population and among health professionals; at-risk populations were not assessed.

\section{Revue systématique de la recherche sociocomportementale sur le VIH/sida en Jordanie}

RÉSUMÉ La présente revue systématique a permis d'évaluer l'ampleur de la recherche sur le VIH/sida menée en Jordanie en relation avec des critères sociaux et/ou comportementaux. Les bases de données MEDLINE, CINAHL, PsycINFO et OVID (1980-2009) ainsi que les archives de résumés 2000-2009 de I'International AIDS Society [Association internationale de lutte contre le sida] ont été consultées. Les revues existantes et les études primaires ont été croisées pour obtenir davantage de références, et la littérature non publiée ainsi que les essais en cours ont été étudiés en contactant des experts et des chercheurs en activité dans ce domaine. Google Scholar a été utilisé pour faire des recherches dans des revues régionales et locales pratiquant l'examen collégial qui ne faisaient pas partie des bases de données mentionnées ci-dessus. Des recherches ont également été menées dans la littérature en langue arabe. Seules huit études ont été identifiées; toutes étaient des études transversales descriptives, soit quantitatives, soit qualitatives. Des échantillonnages de commodité ont été utilisés dans la majorité des études, limitant de manière importante la possibilité de généraliser les résultats. Les études étaient axées sur les connaissances et les attitudes du public et des professionnels de santé en matière de VIH/sida ; les populations à risque n'ont pas été évaluées.

${ }^{1}$ School of Nursing, Hashemite University, Zarqa, Jordan \& Sultan Qaboos University, Muscat, Oman (Correspondence to E. Alkhasawneh: emanursing@yahoo.com). 2Social Intervention Group, School of Social Work, Columbia University, New York, New York, United States of America. ${ }^{3}$ School of Social Work, Jordan University, Amman, Jordan.

Received: 09/06/10; accepted: 03/03/11 


\section{Introduction}

Available evidence suggests that HIV prevalence in Middle Eastern countries is low, with an average of $0.2 \%$. Although between 2001 and 2009 the epidemic was controlled in most regions of the world and prevalence rates in the Middle East and North Africa were still low, it has increased from $0.1 \%$ to $0.2 \%$; the number of new infections doubled between 2001(36000) and 2009 (75 000); the actual number of people living with HIV/AIDS also doubled from 180000 in 2001 to 460000 in 2009 [1].When comparing with international HIV data and other socioeconomic indicators, it is suggested that current prevalence rates are likely to be underestimated, on average by $0.2 \%$ to $1 \%$ [2], and reliable data are still limited making it a challenge to estimate actual numbers [1].

By the end of 2009 there were only 850 officially registered HIV cases Jordan [3], which places the prevalence at $<0.2 \%$ [4]. Only $25 \%(n=211)$ of the registered HIV/AIDS cases were Jordanians; the rest were immigrants. The age range for most of the people diagnosed with HIV is between 20 and 49 years [5]. Currently, the male/female sex ratio is $4: 1$. Fear of stigma may reduce testing and care-seeking behaviour and this, together with an inadequate surveillance system, suggests that the true number of people living with HIV exceeds the number of officially registered cases $[1,4,5]$. Moreover, little is known about transmission patterns and structural forces that drive the HIV epidemic in Jordan. Most HIV cases in Jordan are attributed to sexual contact (60\%), but it is not clear whether it is homosexual or heterosexual, followed by unknown causes (18.2\%), blood transfusion (16.5\%), injection drug use (3.3\%), and mother-to-child transmis$\operatorname{sion}(1.8 \%)[4]$.

Overall, HIV research in the Middle East is limited because of the low prevalence of the disease, stigma about the topic and conservative cultural norms [6]. Taboos and strict values surrounding sexuality outside and within marriage make it challenging to examine the sexual behaviour of Jordanian men and women [5-7]. Stigma and conservative beliefs surrounding socially unacceptable behaviours - sex work, homosexuality and drug use-limit the number of research studies that examine HIV risk behaviours among high risk groups. Studies on HIV/AIDS in Jordan have been particularly absent compared to other Middle Eastern countries such as Egypt and Lebanon [7]. In the meantime, the incidence of HIV/AIDS is rising and without empirical data from epidemiological, socio-behavioural and intervention research, it is difficult to understand the dynamics of the virus's spread and develop interventions that can prevent the currently low rate of HIV in Jordan from increasing [8-11].

Therefore, the objectives of this paper were to review available HIV studies conducted in Jordan and to discuss implications for future research in the country. The paper aims to address the following research questions:

1. What is the state-of-the-science on HIV/AIDS research in Jordan?

2. What types of HIV/AIDS studies have been conducted in Jordan (population-based, intervention, surveys, cross sectional studies)?

3. What are the gaps in HIV research in Jordan?

\section{Methods}

\section{Literature search}

An electronic literature search of MEDLINE, CINAHL, PsycINFO and OVID from 1980 to 2009 was carried out by reviewers during the period September 2009 to January 2010. The International AIDS Society abstract archives from 2000 to 2009 were also searched. In addition, existing reviews and primary studies were crossreferenced for further citations and we searched for unpublished literature and ongoing trials by contacting experts and active researchers in the field. The search included key words specific to HIV/AIDS, study designs (e.g. descriptive, case-control, comparative), and sample characteristics (e.g. Muslim, Islam, Jordan, Jordanian, Arabs, Middle East). No language limitation was imposed. Two of the authors are bilingual so searches were conducted in Arabic literature as well. Using Google Scholar, we supplemented our database search with a search in peer reviewed publications published in other local or regional journals that are not included in the above-mentioned databases.

\section{Inclusion criteria}

We identified studies from peer-reviewed journals that used experimental, cross-sectional or descriptive methodologies. We included all studies that reported research on HIV/AIDS in Jordan, involved participants from Jordan, or were related to HIV/AIDS in Jordan. We included studies that measured any behavioural and/or social outcomes (e.g. unprotected sex, risky behaviours, knowledge of HIV, attitudes about HIV) as relevant markers of HIV risk. Since the target of the paper was to systematically review peer-reviewed, published literature, we did not include country reports or reports by international organizations. Studies that did not report a behavioural or social outcome were excluded; as a result, we excluded 2 studies because they primarily and solely focused on biological factors related to HIV, 1 of the studies estimated the prevalence of the most important sexually transmitted infections (STIs) among a group of symptomatic and asymptomatic women in Jordan, but did examine any behavioural factors that might contribute to the occurrence of STIs [12]. The second study was a seroprevalence study conducted to 
examine HIV infection in Jordan and did not examine behavioural or social factors in relation to HIV [13].

All the articles were initially screened by the authors to exclude studies that were not relevant. The authors met to agree on the initial screening criteria using a small subset of abstracts to ensure that they reached a high level of agreement; all studies that met the inclusion criteria were reviewed by the researchers. The authors were able to identify authors, funding and other characteristics of studies under analysis. A complete review of each study was conducted by all the authors, who read each study and decided on its methodological relevance to this review.

\section{Data extraction}

The authors decided to include all the data available in the studies.

\section{Analysis and assessment of study quality}

We summarized the state of the science on research in the area of HIV/ AIDS in Jordan, with a secondary aim of assessing the quality of the existing studies. Since all studies were descriptive and cross-sectional, we provided a narrative summary and critical analysis. We assessed the following aspects of the study quality: (1) study design; (2) method of selecting participants for the study; (3) sampling; (4) data collection instruments and methods; and (5) data analytical procedures.

\section{Results}

We were only able to identify 8 studies that were relevant to our research questions and were included in the review. Four studies were excluded since they only reviewed biological factors related to HIV. The studies were conducted between 1987 and 2005. A summary of articles is provided in Table 1.

\section{Topics covered}

Seven of the reviewed articles examined HIV knowledge and attitudes of Jordanian citizens or health professionals and the readiness of the Jordanian health care system and personnel to address the emerging HIV cases/epidemic.

Attitudes toward HIV: Four of the reviewed studies focused on data about attitudes towards people living with HIV and HIV preventive behaviours [14-17] Three of the reviewed studies reported that young people in Jordan, including nursing students, nurses and medical doctors, did not have positive attitudes to people with HIV [14,17]. Attitudes were relatively more favourable among doctors than among nurses [17]. One study demonstrated that only $15 \%$ of dentists were willing to serve an HIV-positive patient [15]. The studies concluded that negative social attitudes towards HIV-positive individuals contributed to social discrimination and were especially detrimental when practised by health professionals.

Knowledge of HIV: In addition to attitudes, 3 studies collected information about the level of HIV prevention knowledge among the general population in Jordan, primarily youth, and among health professionals $[14,17,18]$. The studies showed that the level of knowledge was fairly low both for youth and medical students. Compared to the mid-1990s [14], the percentage of nurses and doctors who had heard of HIV/ AIDS rose to $76 \%$ by 2002 , although HIV knowledge was often superficial and not accurate [17]. Lack of accurate HIV/AIDS knowledge and numerous misconceptions about HIV created a basis for negative and discriminatory attitudes towards people with HIV [17].

Preparedness of health care system: Health care professionals are not entirely responsible for the limited awareness of HIV. Two of the reviewed studies examined the preparedness of health care providers, 1 study reported that the 2 medical schools' educational curriculum did not address the issue of HIV and students and practitioners had limited exposure to people with HIV/ AIDS [14]. Assessment of the health care system indicated that health care facilities also were not well-prepared to provide care for people with HIV $[19,20]$; the authors described the situation as "a discrepancy between reality and rhetoric" when commenting on the lack of services and facilities despite numerous pledges and commitments at the official level.

\section{Methodological quality}

Study designs: All HIV/AIDS studies included in the review were descriptive cross-sectional studies; 6 were quantitative and 2 were ethnographic qualitative studies.

Sampling: The studies had sufficient sample sizes. In 2 of the quantitative studies the sample size ranged from 126 to 1124 cases $[13,18]$. On average, the 2 qualitative studies $[19,20]$ had smaller, but sufficient, sample sizes $(n=27)$ for conducting analysis for qualitative data. However, all 8 studies reviewed used available (or convenience) sampling techniques; in addition, none of the studies targeted high-risk populations such as men who have sex with men (MSM), sex workers and drug users.

Data collection methods and measurement instruments: Both quantitative and qualitative methodologies were equally presented among the available HIV research in Jordan. In the 2 quantitative studies where instruments were modified from standardized scales, the psychometric properties were not tested and reported in the new population $[16,18]$. Only 1 study conducted biological testing of participants to determine their HIV status [13]. The remaining 4 studies relied on self-reported data collection methods. The assessment of the qualitative studies was more thoroughly developed and included detailed observational protocols for observers $[19,20]$. 


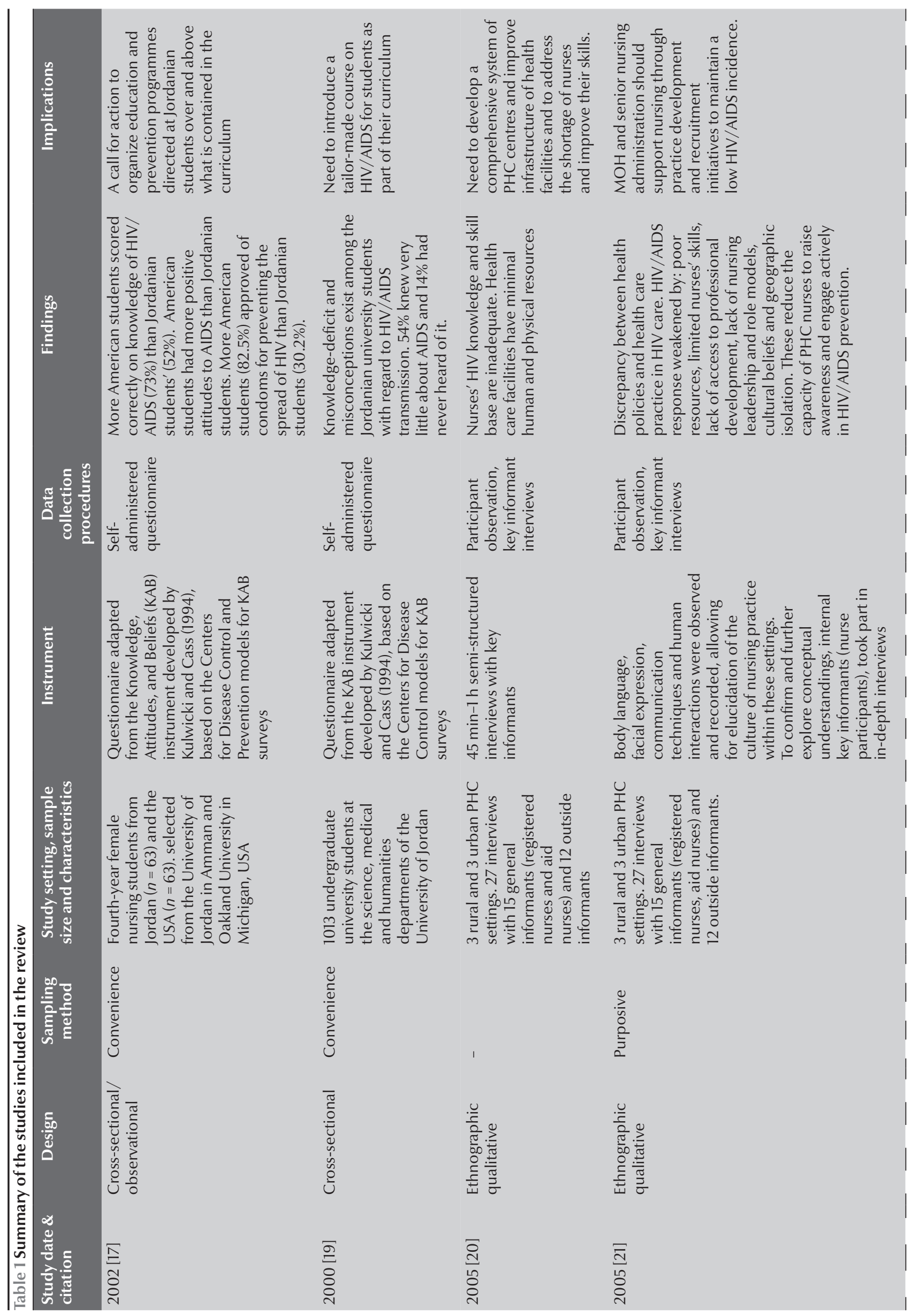




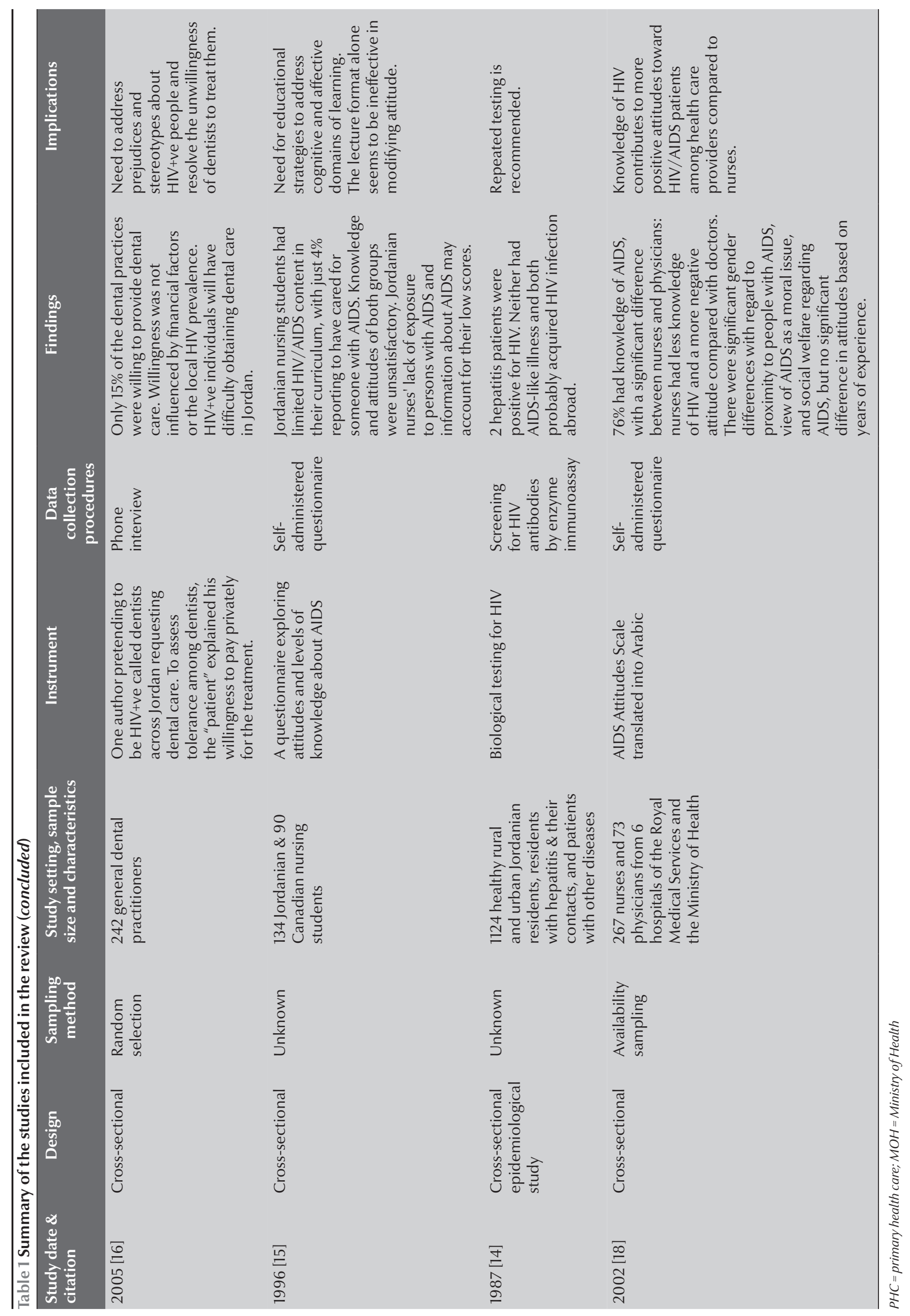


Analytical approach: All the studies were limited to descriptive analyses of findings and relied solely on univariate analysis and reporting of frequency data by various groups.

Researchers: Most of the studies included were conducted by medical doctors and all were from the health field. Only the Ministry of Health was involved in planning and implementing studies related to HIV/AIDS.

Funding: Acknowledgement of funding was not mentioned in any of the 8 reviewed studies.

\section{Discussion}

The systematic review conducted for this paper clearly shows that behavioural research on HIV/AIDS in Jordan is limited, even compared to other Middle Eastern countries. Those studies that were identified assessed HIV/AIDS knowledge, beliefs and/or attitudes of the general population or the level of preparedness of health professionals to deal with HIV positive individuals. The studies were fairly simple in design: all were descriptive cross-sectional studies conducted by health care professionals and the majority recruited participants through convenience samples, which severely undermines the generalizability of the findings. No studies using longitudinal, randomized or quasi-experimental were identified, none tested and evaluated HIV/AIDS prevention and intervention approaches, and none examined AIDS knowledge among high-risk groups such as sex workers, MSM, injection drug users (IDUs) and migrant workers. Such reluctance to study these groups might be due to the strict Arabic social norms related to addressing sexual activity and sexuality, difficulty to reach such populations. Funding source was not mentioned in any of the studies. This point suggests a lack of funding for research studies in Jordan, especially studies that target HIV/AIDS; however, reports in the grey literature were funded by different national and international organizations

We acknowledge that this paper has some limitations. Our main goal was to systematically review the literature available in peer-reviewed journals and thus we excluded data available in so-called grey literature. However, most HIV research in Jordan is conducted outside of academia at the level of the Ministry of Health or by nongovernmental international organizations; the results are rarely published in peer-reviewed journals and thus have never been validated or distributed to international reader. The strength of this review is its comprehensive search of published sources in regional, national and international databases, both in English and Arabic. This is the first systematic review of HIV/AIDS research in Jordan and one of the very few in the Middle East and North Africa.

While Jordan is considered to have a low prevalence of HIV, the incidence is increasing. Several factors have been reported to be associated with the low prevalence : 1) the norms and traditions of a conservative society dictate social behaviour in the country $[11] ; 2$ ) male circumcision is almost universal in Muslim communities [21]; and 3) alcohol intake is low [22]. However, while a conservative society may be seen to contribute to a low HIV prevalence, it should be remembered that India, which is a conservative society with patriarchal relations between men and women, now has an HIV/AIDS prevalence of $0.36 \%$ with the threat of wider spread [23]. Patriarchal norms can create power imbalance in sexual relations, which can contribute to an increase in risky sexual behaviour [8] and gender inequalities in relationships put women at higher risk for HIV infection [24-28].

Factors that may be driving the increasing incidence of HIV in Jordan include the stigma associated with HIV $[1,11]$, gender inequalities $[23,29]$, a demographically young population, increased unemployment rates [5], migration and the political instability of surrounding countries [5], and labour migration [23,29]. Economic hardship has meant that young Jordanians are delaying marriage, which has led to more sexual contacts outside of marriage. High unemployment has left young people free to spend their spare time in cafés and amusement centres or working as unskilled labourers, thus exposing them to potential pressure for risky sexual behaviour [4]. Political instability in the region and the influx of a large number of migrant workers to Jordan, the return of 300000 Jordanians as a result of the Gulf War and the migration of hundreds of thousands of Iraqis to Jordan as a result of the 2003 War have created multiple challenges for the country. This influx has resulted in an increase in unemployment rates and placed a strain on the education system. Vulnerability to risks associated with instability and migration create an environment that puts local people at higher risk for HIV [30]. Large displaced and migrant populations, mobility of migrant workers from high endemic countries into Jordan, poverty and gender inequalities are often associated with increases in sex work and casual sex.

Personal factors also increase the risks of the spread of HIV; although Jordanians know about and have access to condoms, they still do not use it as a protective measure. A recent unpublished study of workers in industrial zones and small business owners in Jordan revealed that most participants knew about AIDS, had heard about condoms and had easy access to them; however, a significant number of the study participants reported exchanging sex for money, contacting a commercial sex worker and rarely using condoms [8]. In addition, only $15 \%$ of MSM in Jordan reported using a condom during their most recent episode of intercourse with a male partner [31]. 
These circumstances might be affecting sexual practices among Jordan's general population and various risk groups and may have an impact of the spread of HIV in the country. However, very little information is available on these factors.

Prevention is the foremost viable strategy in countries with low prevalence of HIV and in the last 2 years, the Jordanian government has increased the attention paid to preventing the HIV epidemic from gaining a foothold in the population. There have been efforts to encourage nongovernmental organizations to conduct HIV studies among high-risk groups. Family Health International, in collaboration with the USAID mission in Jordan, has conducted several knowledge, attitudes, and practices (KAP) studies with men and women working in industrial zones [8] with youth [4] and with sex workers [8]. However, findings from these studies are only available in annual reports and have never been published in peer-reviewed scientific journals; in addition, the National Strategy on HIV/ AIDS indicated that there appears to be almost no information available on the vulnerable groups in Jordan. Even numbers for well-defined groups, such as the military and prisoners, are not readily available. The only figures relating to vulnerable groups are those from law enforcement services on prisoners. It was estimated that around $6 \%$ of prisoners were injecting drug users [32].

Thirty years after HIV was first described, only 8 peer-reviewed, published HIV/AIDS studies exist in Jordan and none focused on prevention or intervention [33]. There is an urgent need therefore for more multidisciplinary research using diverse methodologies to be conducted in order to better understand the HIV/AIDS situation in Jordan so as to inform prevention and intervention policies. Such research should focus on the general population, such as children, families, as well as on high-risk groups, particularly migrant workers and their sex partners, sex workers and their clients, and men having sex with men [6]. There is also a need for research that evaluates the factors contributing to HIV/AIDS in Jordan, such as gender inequalities, migration, poverty, stigma and risky sexual behaviours. In order to encourage such research, training of Jordanian researchers on different types of HIV/AIDS research (epidemiological, population-based, prevention, intervention) is necessary. This training could take place in university research centres that focus on medicine and health. Such training would promote scientificallybased research on HIV, and would also assist the country in being better prepared to address HIV, especially among at-risk groups. At the same time, adequate funding for different types of HIV research is needed in Jordan. Without a funding commitment, HIV behavioural research in Jordan will continue to lag far behind other countries in the region and the world, as identified by this review.

\section{References}

1. UNAIDS. Fact sheet. Middle East and North. Increasing HIV prevalence, new HIV infections and AIDS-related deaths Africa (http://www.unaids.org/documents/20101123_FS_ mena_em_en.pdf, accessed 23 February 2012).

2. Pierre-Louis M, Jenkins C, Robalino D. The threat of HIV/AIDS in the Middle East And North Africa region. Paper presented at the 14th International Conference on AIDS, Barcelona, Spain 7-12 July 2002.

3. AIDS statistics. Amman, Jordan, Ministry of Health, 2009.

4. USAID. Success stories: HIV/AIDS. AIDS hotline reaches youth in Jordan. (http://www.usaid.gov/our_work/global_health/ aids/News/successpdfs/jordanstory.pdf, accessed 23 February 2012).

5. UNGASS Country Report: Hashemite Kingdom of Jordan 2006-2007 (http://data.unaids.org/pub/Report/2008/ jordan_2008_country_progress_report_en.pdf, accessed 23 February 2012).

6. Akala FA, Jenkins C. Preventing HIV/AIDS in the Middle East and North Africa: a window of opportunity to act. Washington DC, World Bank, 2005.

7. Abu-Raddad LJP et al. Analytic insights into the population level impact of imperfect prophylactic HIV vaccines. Journal of Acquired Immune Deficiency Syndromes, 2007, 45:454-467.

8. Knowledge, attitudes, and practices survey of workers in qualified industrialzones and small businesses in Jordan. Family Health International \& USAID, 2008 (http://pdf.usaid.gov/pdf_docs/ PNADM793.pdf, accessed 23 February 2012).
9. Jenkins C. Vulnerability to HIV/AIDS in the Middle East and North Africa: a socio-epidemiology overview. Paper presented at the 15th International AIDS Conference, 11-16 July, 2004, Bangkok, Thailand (Satellite meeting of global researchers of HIV/AIDS in the Middle East and North Africa Region).

10. Jenkins C, Robalino D. HIV/AIDS in the Middle East and North Africa: the costs of inaction. Washington DC, World Bank, 2003.

11. Sufian S. HIV/AIDS in the Middle East and North Africa. Middle East Report (New York, NY), 2004, 233:6-9.

12. Mahafzah AM et al. Prevalence of sexually transmitted infections among sexually active Jordanian females. Sexually Transmitted Diseases, 2008, 35:607-610.

13. Toukan AU, Schable CA. Human immunodeficiency virus (HIV) infection in Jordan: a seroprevalence study. [Case Reports]. International Journal of Epidemiology, 1987, 16:462-465.

14. Al-Ma'aitach R. Jordanian and Canadian nursing students' knowledge about AIDS. International Nursing Review, 1996, 43:89-92.

15. El-Maaytah $\mathrm{M}$ et al. Willingness of dentists in Jordan to treat HIV-infected patients. Oral Diseases, 2005, 11:318-322.

16. Petro-Nustas W, Kulwicki A, Zumout A. Students' knowledge, attitudes, and beliefs about AIDS: a cross-cultural study. Journal of Transcultural Nursing, 2002, 13:118.

17. Saleh F. Nurses' and physicians' attitudes towards AIDS in Jordan. Jordanian Royal Medical Services, 2002, 9:51-55.

18. Petro-Nustas W. University students' knowledge of AIDS. International Journal of Nursing Studies, 2000, 37:423-433. 
19. Nawafleh H, Francis K, Chapman Y. The influence of HIV/ AIDS on the practice of primary care nurses in Jordan: Rhetoric and reality. International Journal of Nursing Practice, 2005 11:200-205.

20. Nawafleh H, Francis K, Chapman Y. Jordan's vulnerability: A population at risk of HIV/AIDS. Contemporary Nurse, 2005, 19:197-210.

21. Male circumcision: global trends and determinants of prevalence, safety and acceptibility. Geneva, World Health Organization and Joint United Nations Programme on HIV/AIDS, 2007.

22. Public health problems of alcohol consumption in the Region. Technical paper presented at the Fifty-third Session of the Regional Committee for the Eastern Mediterranean, September 2006 (EM/RC53/4) (http://www.emro.who.int/rc53/media/ pdf/EMRC5304En.pdf, accessed 23 February 2012).

23. Preventing HIV/AIDS in the Middle East and North Africa. A window of opportunity to act. Washington DC, World Bank, 2005.

24. El-Bassel $\mathrm{N}$ et al. Intimate partner violence prevalence and HIV risks among women receiving care in emergency departments: implications for IPV and HIV screening. Emergency Medicine Journal, 2007, 24:255-259.

25. Hoffman $\mathrm{S}$ et al. HIV risk behaviors and the context of sexual coercion in young adults' sexual interactions: results from a diary study in rural South Africa. Sexually Transmitted Diseases, 2006, 33:52-58.
26. Kim Jb et al. Exploring the role of economic empowerment in HIV prevention. AIDS (London, England), 2008, 22(Suppl. 4):S57-S71.

27. Kulwicki AD, Cass PS. An assessment of Arab American knowledge, attitudes, and beliefs about AIDS. Journal of Nursing Scholarship, 1994, 26(1):13-17.

28. Shawky $S$ et al. HIV surveillance and epidemic profile in the Middle East and North Africa. Journal of Acquired Immune Deficiency Syndromes, 2009, 51(Suppl. 3):S83-S95.

29. UNICEF. Jordan. Statistics (http://www.unicef.org/infobycountry/jordan_statistics.html, accessed 23 February 2012).

30. Jordan Population and Family Health Survey 2007. Calverton, Maryland, USA: Department of Statistics [Jordan] and Macro International Inc., 2008 (http://www.measuredhs.com/pubs/ pdf/FR209/FR209.pdf, accessed 23 February 2012).

31. Country Progress Report. Hashemite Kingdom of Jordan Report to the Secretary General Of the United Nations on the United Nations General Assembly Special Session On HIV/ AIDS January 2008-December 2009 (http://www.unaids. org/es/dataanalysis/monitoringcountryprogress/2010progr essreportssubmittedbycountries/file,33630,es.pdf, accessed 17 April 2012).

32. National AIDS Strategy. Amman, Jordan, Ministry of Health, 2005.

33. Abu-Raddad LJ et al. Characterizing the HIV/AIDS epidemic in the Middle East and North Africa: time for strategic action. Washington DC, World Bank, 2010.

\section{Situation of HIV testing and counselling policies and practices in the Eastern Mediterranean Region}

HIV testing and counselling constitute a major bottleneck in scaling up HIV prevention, treatment and care services in the WHO Eastern Mediterranean Region. The situation of HIV testing and counselling policies and practices in the Eastern Mediterranean Region (EMRO Technical Publications Series, No. 38) provides policy-makers with an up-to-date and comprehensive review of the situation in 2010 and argues powerfully for an effective public health approach to HIV testing and counselling.

Further information about this and other EMRO publications is available at: http://www.emro.who.int/publications/ 